\title{
Histological Effects Aqueous Extract of Allium sativum (Alliaceae) Bulb on Bone and Spleen of Adult Wistar Rats
}

\author{
*10DIASE, DE; OSAZEE LO
}

\author{
*Department of Anatomy, School of Basic Medical Sciences, College of \\ Medical Sciences, University Of Benin, Benin City, Nigeria. \\ E-mail: daniel.odiase@uniben.edu
}

\begin{abstract}
Allium sativum, commonly known as garlic is a member of the Alliaceae family and it is one of the earliest known medicinal plant. The aim of this study is to evaluate the histological effects of aqueous extract of Allium sativum bulb on selected organs (bone marrow and spleen) of the mononuclear phagocyte system using adult Wistar Rats. Twenty adult Wistar rats were grouped into four experimental groups: A, B, C and D. Rats in group A served as control and were administered distill water daily for period of five weeks. While groups B, C and D were administered aqueous extract of Allium sativum bulb orally at doses of 150, 300 and $600 \mathrm{mg} / \mathrm{kg}$ body weight daily for a period of five weeks respectively. At the end of the experiment the animals were sacrificed, the spleen and bone marrow were harvested and fixed in $10 \%$ buffered formalin for histological studies. Photomicrographs of processed slides were taken using light microscope. The result obtained in the various treatment groups revealed in a non-dose dependent fashion increase in cellularity and myeloid- erythoid cells in the bone marrow and mild lymphoid follicular activation accompanied by sinus histiocytosis in the spleen. In conclusion, administration of aqueous extract of Allium sativum bulb showed enhanced immunostimulatory properties in the bone marrow and spleen of adult Wistar rats. Dietary supplement with Allium sativum can boost the immunity of Individuals living in communities with low socio-economic status who are prone to malnutrition and infections. CJASEM
\end{abstract}

\section{https://dx.doi.org/10.4314/jasem.v21i3.15}

Keywords: histological, sinus histiocytosis, mononuclear phagocyte system, cellularity myeloid- erythoid cells.

Medicinal plants a rich sources of vitamins and substances which are claimed to induce immune responsive especially granulocytes, macropages, natural killer cells and competent functions (Sampath et al, 2010). In recent year, immunostimulatory activity had been reported in numbers of medicinal plants and various secondary metabolites (e.g. alkaloids, glycosides, saponins, flavonoids, coumarins, and sterols) exhibit a wide range of immunomodulating activity (Fulzele et al, 2003). Some medicinal plants may stimulate the immune system, and Terminalia arjuna), and some may suppress the immune response (Clement et al, 2010; Manu and Kuttan 2009).

Allium sativum, (garlic) is a member of the Alliaceae family and it's amazing famous power against diseases is due to a combination of both direct and in direct action. In vitro garlic extracts excites the rat and human lymphocytes and the diallyltrisulfide of garlic has been shown to enhance activation of T lymphocytes (Feng et al,1994; Lau et al, 1991). It also enhanced antibody production against different species of bacteria and this showed that it increases the activity of B lymphocytes
(Szigeti et al, 1991). Garlic extracts had been found to suppress pro-inflammatory cytokines like IL-2 and elevate inters lukin (IL) -10 and IL-12 in monocytes (Hodge et al, 2002). Garlic preparations encouraged the macrophage infiltration; cytokine release and the addition of different garlic extracts enhance the engulfment ability of phagocytes as well as the secretory metabolism of macrophages (Romano et al, 1997; Dirsch et al, 1998; Gomez-Flores et al, 2000).

Aged Garlic Extract excites the proliferation of spleen cells, release of cytokines and phagocytosis by peritoneal macrophages. Immune enhancing effects of commercial garlic preparations was studied and it was found that aged garlic extract was the most effective for improving immune factors, specifically macrophage and T-lymphocyte activity (Tadi et al, 1990).

Objective: The objective of this work is to evaluate the effects of Allium sativum on bone and spleen of Adult Wistar rats. Specifically,effects on immunity and anatomical configuration as a result of administration of the extract. 


\section{MATERIALS AND METHOD}

Collection and Identification of Allium Sativum: Allium sativum bulbs were purchased at Ikpoba hill market, in Benin metropolis. The bulbs were identified and authenticated in the pharmacognosy Department of the University of Benin by $\mathrm{Mr}$. Sunny Nweke.

Extract Preparation: The bulbs were peeled, blended using a blender and soaked in distilled water for $12 \mathrm{hrs}$. The aqueous extract was filtered using a Buchner funnel and Whatman No.1 filter paper. Dried aqueous extracts were obtained after removing the solvent by evaporation under reduced pressure using Rotary evaporator. The extract was stored in an air-tight container and kept in the refrigerator at $4^{\circ} \mathrm{C}$ until it was required for use.
Test Animals: Twenty (20) Wistar rats of both sexes, weighing between $200-270 \mathrm{~g}$ were used for this study. The animals are inborn rats obtained from the Animal House Unit of the Department Anatomy, University of Benin, Benin City. Food and water were provided ad' libitum. Animals were exposed to controlled environmental temperature $\left(28 \pm 2{ }^{\circ} \mathrm{C}\right)$, relative humidity $(50 \pm 5 \%)$ and 12 hour light or dark. The animals were also allowed two weeks under these conditions to acclimatize before the commencement of the experiments.

Experimental Animal and Designs: The Rats were divided into four groups, each group consisting of five animals. All administrations were done orally using an orogastric tube daily for five (5) weeks. The control group also received $1 \mathrm{ml}$ of distilled water via orogastric tube daily

Treatment regime as shown below:

\begin{tabular}{ll}
\hline GROUP & REGIMEN \\
\hline Group A & Control (1ml of distilled water) for 5 weeks. \\
Group B & $150 \mathrm{mg} / \mathrm{kg}$ of body weight of Allium sativum extract \\
& for $5 \mathrm{weeks}$. \\
Group C & $300 \mathrm{mg} / \mathrm{kg}$ of body weight of Allium sativum extract \\
& for 5 weeks. \\
Group D & $600 \mathrm{mg} / \mathrm{kg}$ of body weight of Allium sativum extract \\
& for 5 weeks. \\
\hline
\end{tabular}

Animal Sacrifice: At the end of the experiment the animals were sacrificed under chloroform anesthesia. A ventral lacerectomy was made using surgical blade and forceps. The spleen and bone marrow were removed immediately and blotted dry on a filter paper. The tissues were then fixed in $10 \%$ buffered formalin for routine Haematoxylin and Eosin histological processing using the method of Drury et al., (1976). Finally, photomicrographs of processed slides were taken using the Light Microscope.
Histological Techniques: Excised spleen and bone marrow were fixed by immersion for the histological studies using Bouins fluid for $18 \mathrm{~h}$, dehydrated through series of graded alcohol, cleared in xylene, infiltrated and embedded in molten paraffin wax. Tissue blocks were sectioned at $6 \mu \mathrm{m}$ thickness deparaffinized and stained with Heamatoxylin and Eosin. The sections were examined with the light microscope and photomicrographs of the sections were taken for further analysis

\section{RESULTS AND DISCUSSION}

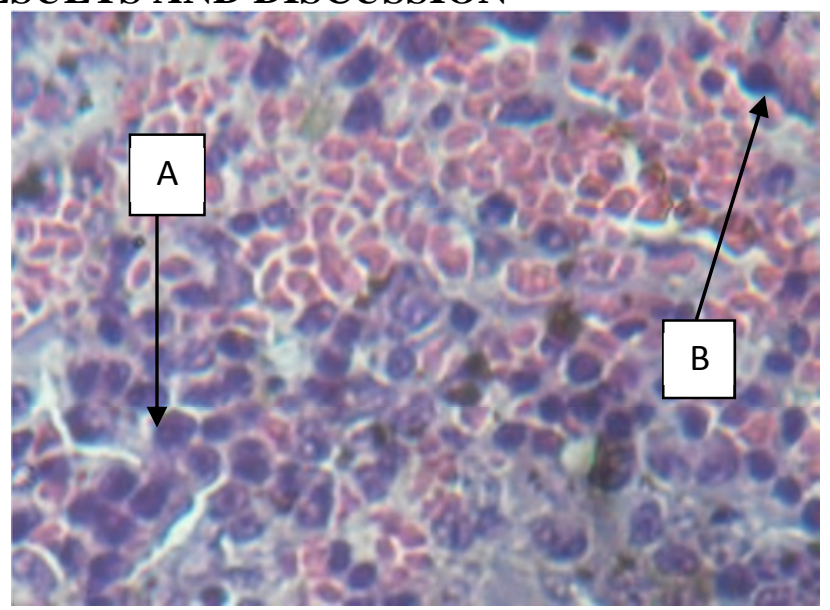

Plate 1 Control: Rat spleen composed of white pulp A and red pulp B (H\&E x 400) 


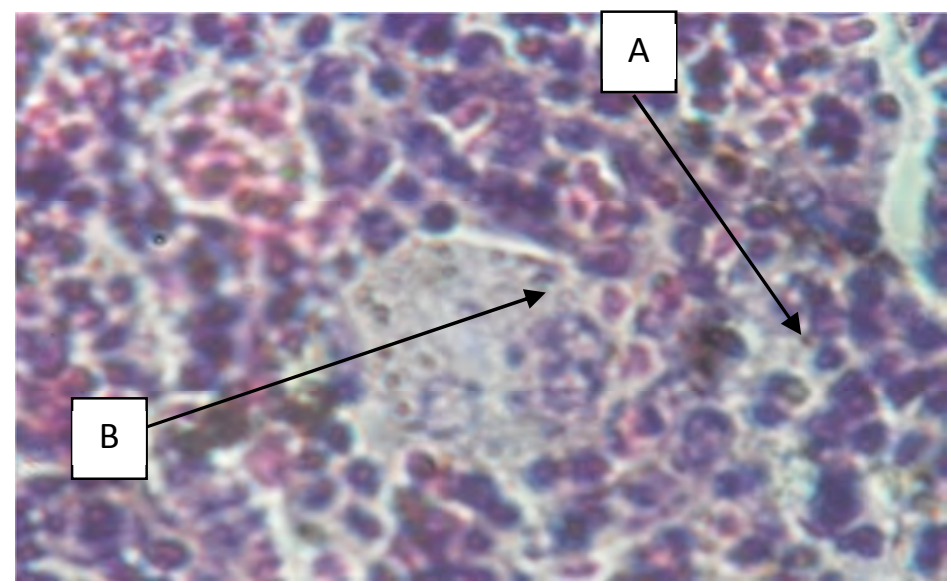

Plate 2: Rat spleen given low dose of extract showing mild lymphoid follicular activation A and mild sinus histiocytosis B (H\&E x 400)

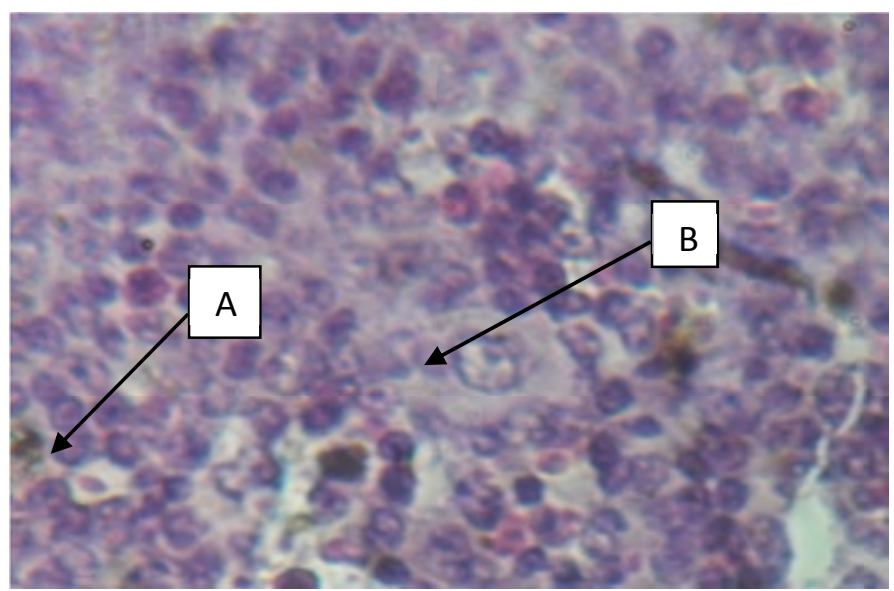

Plate 3: Rat spleen given moderate dose of extract showing moderate follicular activation A and mild sinus histiocytosis B (H\&E x 400)

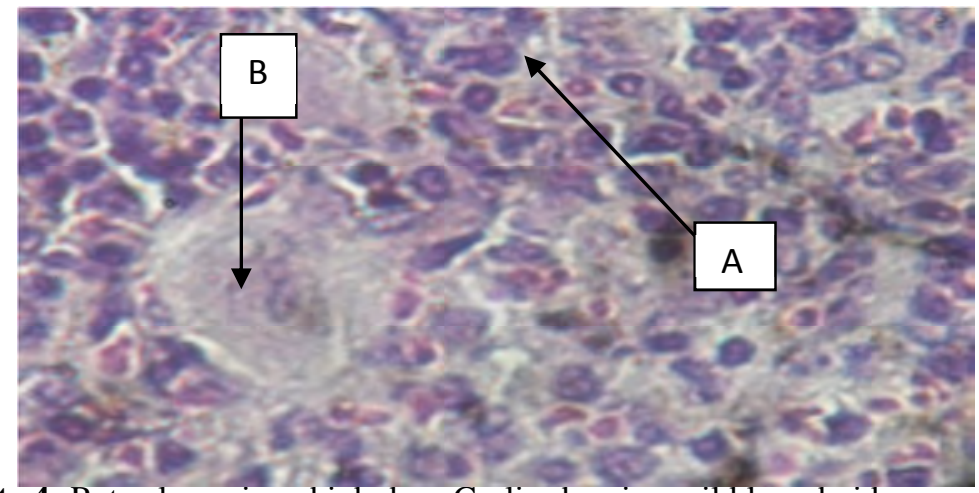

Plate 4: Rat spleen given high dose Garlic showing mild lymphoid

follicular activation A and mild sinus histiocytosis B (H\&E x 400) 


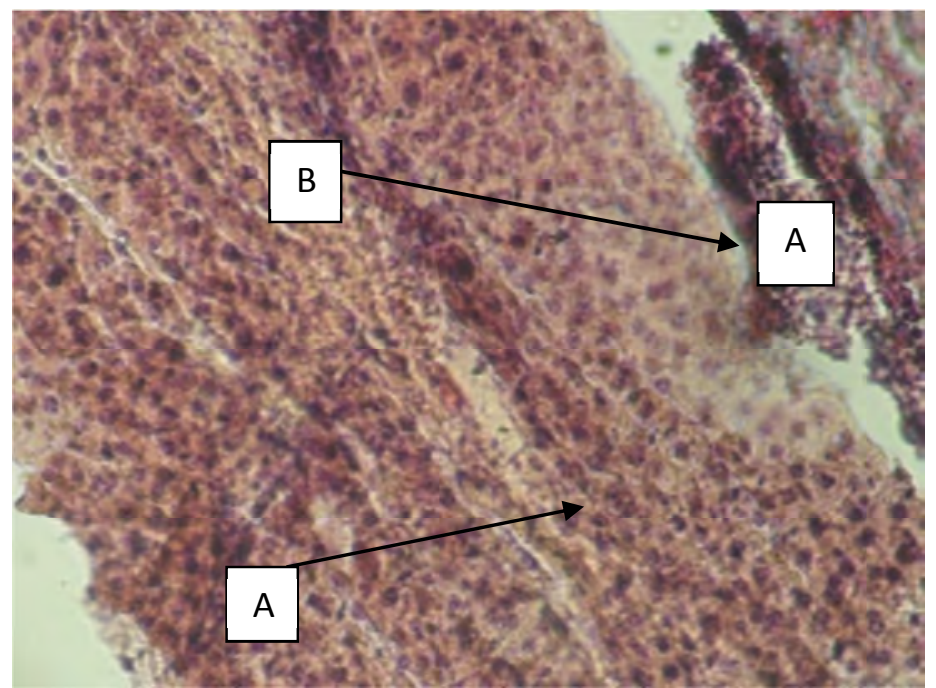

Plate 5 Control: Rat bone marrow showing myeloid-erythroid cells A and bone spicule B (H\&E x 100)

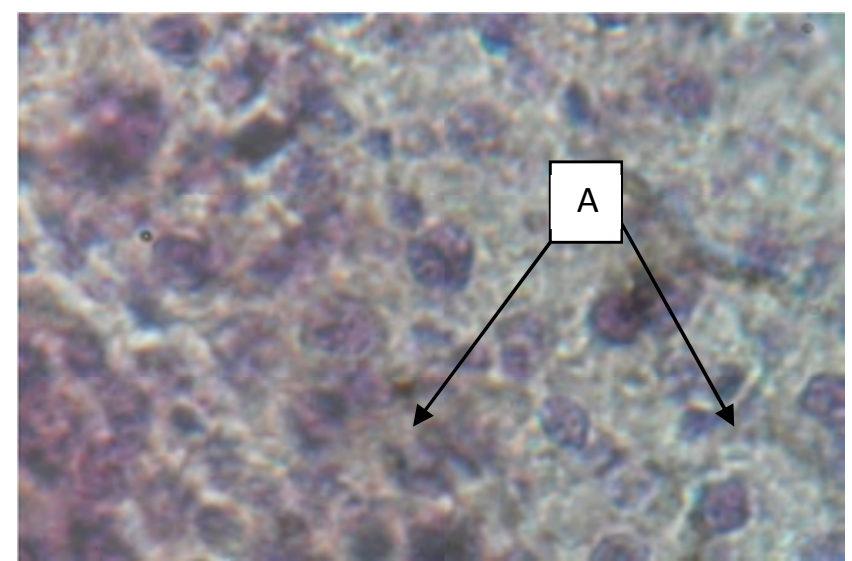

Plate 5b: Higher magnification of the slide (plate 5) above (H\&E x 400)

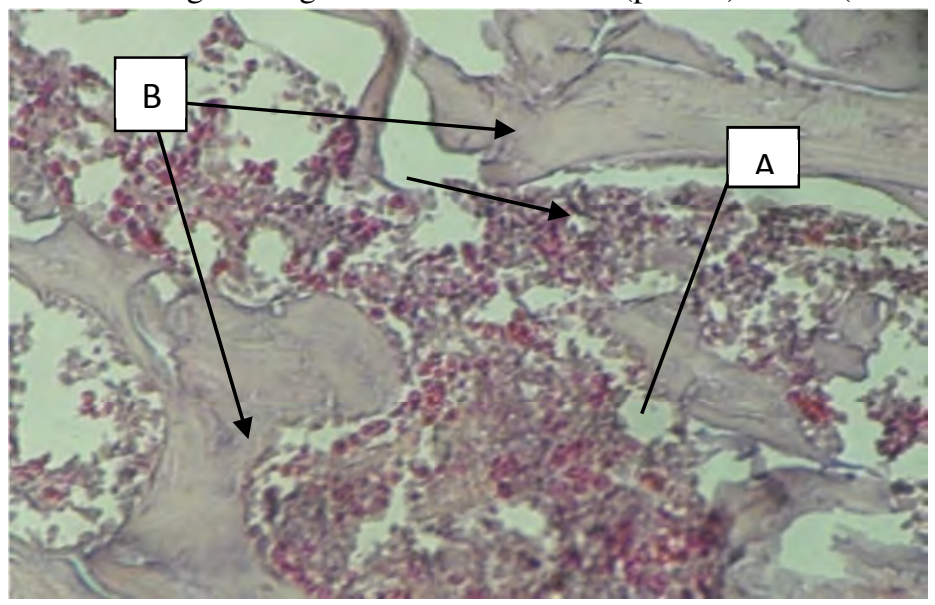

Plate 6: Rat bone marrow given low dose of extract showing mild increase in cellularity A, bone spicule B (H\&E x100) 


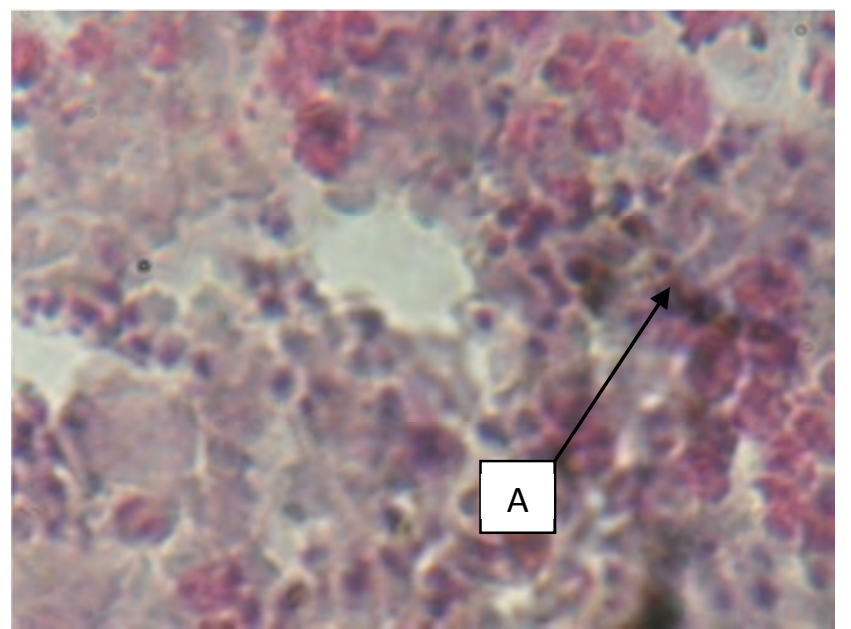

Plate 6b: Higher magnification of the slide (plate 6) above (H\&E x 400)

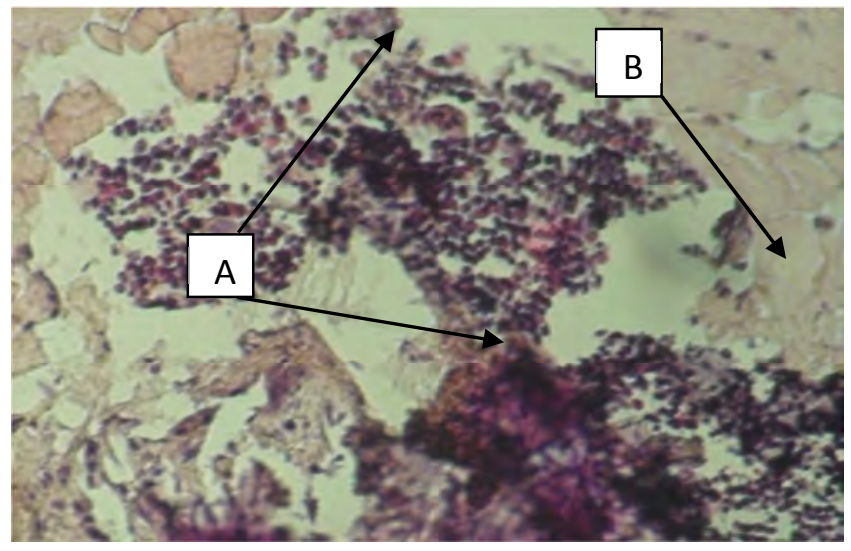

Plate 7: Rat bone marrow given moderate dose of extract showing mild increase in cellularity A, bone spicule B (H\&E x 100)

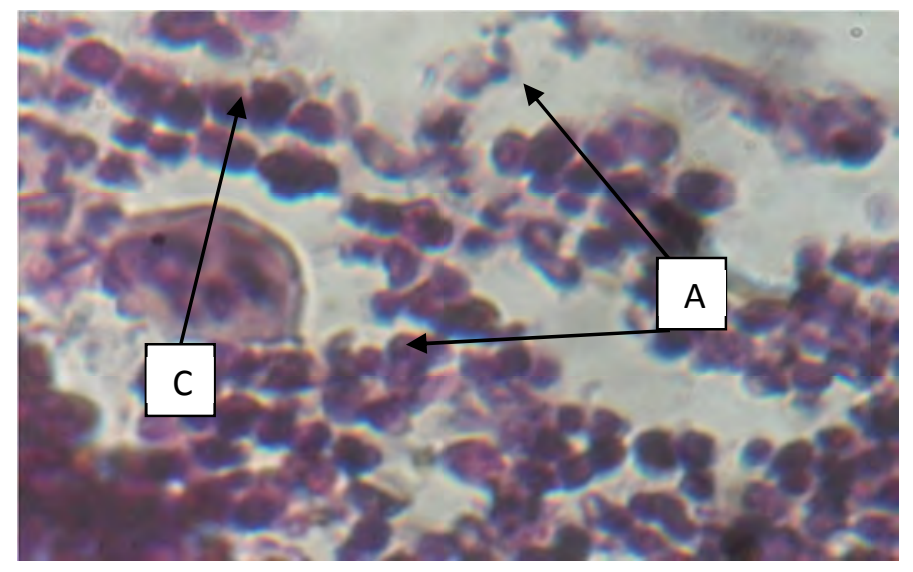

Plate 7b: Higher magnification of the slide 7 above. Showing increased cellularity A, megakaryocyte C (H\&E $\mathrm{x}$ 400) 


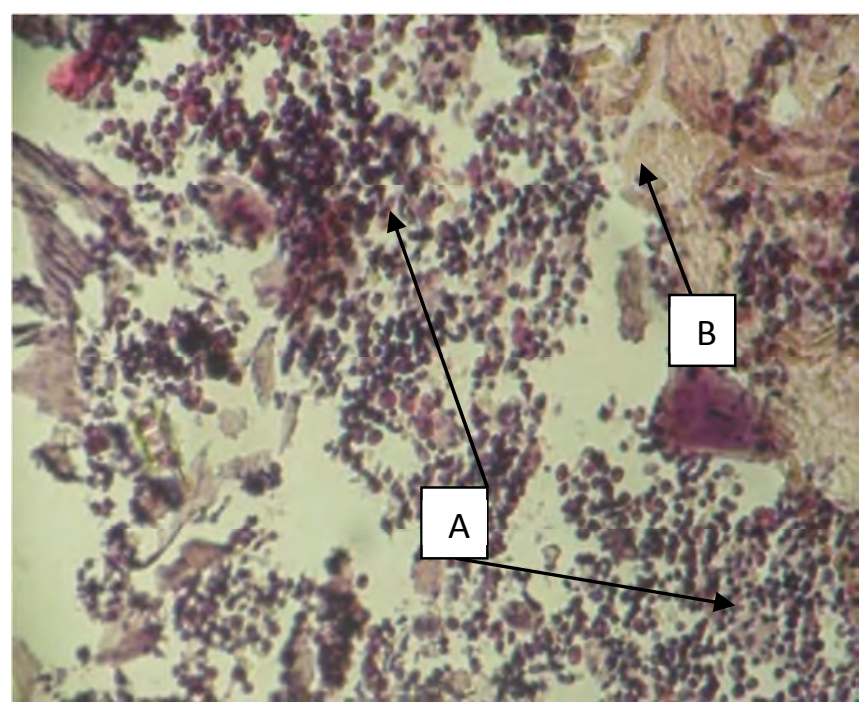

Plate 8: Rat bone marrow given high dose of extract showing mild increase in cellularity A, bone spicule B (H\&E x 100)

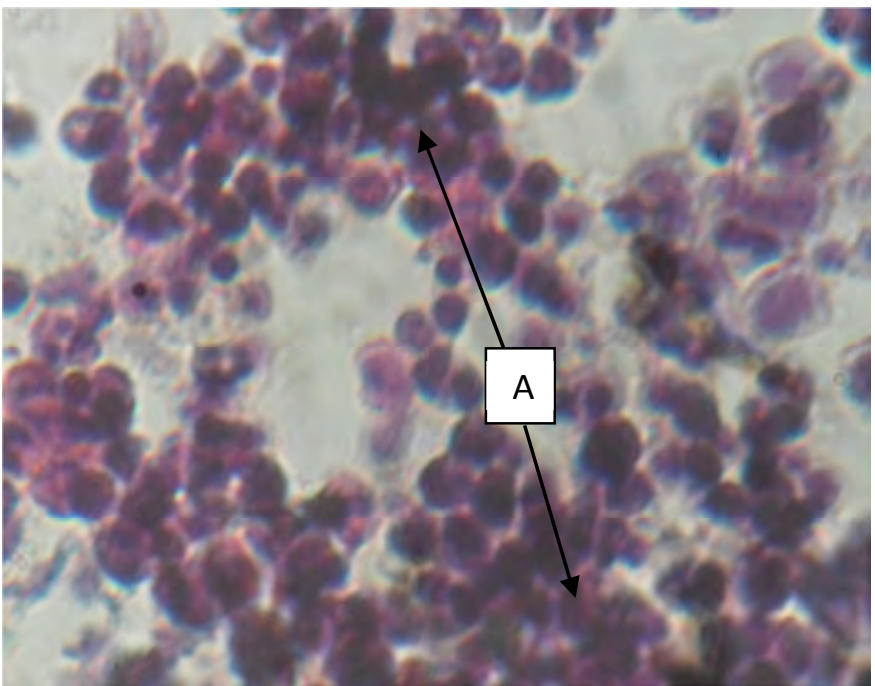

Plate 8b: Higher magnification of the slide 8 above showing mild increase in cellularity A (H\&E x 400)

Macroscopic Findings: The animals in both control and test groups were closely observed macroscopically throughout the period of the experiment. At the end of 5 weeks of study, the entire animals and selected organs (bone marrow and spleen) of the mononuclear phagocyte system, were carefully observed and revealed no observable gross lesions when compared with control group.

Microscopic Findings: Haematoxylin \& Eosin (H\&E) sections of the organs of the mononuclear phagocyte system, revealed some histological changes in the test groups when compared with the control group.

Spleen: Plate 1 showed the photomicrograph of rat spleen in the control group of experimental rats with prominent red and white pulps which is characteristic of normal spleen. However, administration of aqueous extract of Allium Sativum bulbs at low dose resulted in mild lymphoid follicular activation and mild sinus histiocytosis in the spleen as shown in plate 2. Also, treatment with both moderate and high doses of the extract showed similar lymphoid follicular activation and sinus histiocytosis as shown in plates 3 and 4 respectively. Spleen is a centre of activity of the Mononuclear Phagocyte System and can be considered analogous to a large lymph node, as its absence causes a predisposition to certain infections (Brender et al., 2005). The spleen is an immunologic filter of the blood and it is made up of B cells, T cells, macrophages, dendritic cells, natural killer cells and red blood cells. In this study, aqueous extract of Allium sativum bulbs stimulated lymphoid 
follicular activation and sinus histiocytosis in the spleen which is capable of stimulating the production of more lymphocytes and histiocytes and eventually produced more antibodies. These were no evidence of such activation in the control group of the experimental animals.

Bone Marrow: Plate 5, showed normal histological pattern of the bone marrow with prominent bone spicules and some myeloid-erythroid cells. However, administration of aqueous extract of Allium sativum bulbs at low, moderate and high doses to experimental rats resulted in increased cellularity and myeloid- elytroid cells of the bone marrow as shown in plates 6,7 and 8 . This was similar in all the experimental groups hence it was said to have occurred in a non-dose dependent pattern.

The bone marrow is a key component of the lymphoid tissues of the body; all the cells of the immune system are initially derived from the bone marrow through a process called hematopoiesis. During hematopoiesis, bone marrow-derived stem cells differentiate into either mature cells of the immune system or into precursors of cells that migrate out of the bone marrow to continue their maturation elsewhere (More and Pai, 2011; Agrawal et al.,2010). In the control group of experimental animals, the bone marrow showed normal architectural pattern anatomically but in the test groups, aqueous extract of Allium sativum stimulated increase in cellularity and mild activation of myeloiderythoid cell in a non-dose dependent manner. The myeloid series are white blood cells (monocytes and lymphocytes) while the elytroid cells are red blood cells. It also induced the production of megakaryocyte (plasma cell) as shown in $7 \mathrm{~b}$.

The mononuclear phagocyte system (MPS) is defined as a population of cells derived from progenitor cells in the bone marrow, which differentiate to form blood monocytes, circulate in the blood, and then enter tissues to become resident tissue macrophages. Our present research had demonstrated the effects of aqueous extract of Allium sativum (Garlic) on selected organs (bone marrow and spleen) of the mononuclear phagocyte system.

In conclusion, aqueous extract of Allium sativum bulbs increases bone marrow cellularity as evident by increased population of myeloid-erythroid cells. There was activation of splenic sinus histiocytes and lymphoid follicles which is an indication that the extract has immunostimulant activity on the tissue of the mononuclear phagocyte system.

\section{REFERENCES}

Agrawal, S; Surendra, K; Saurabh, C; Gokul, S (2010) . Studies on Immunomodulatory Activity of Capparis zeylanica Leaf Extracts. International Journal of Pharm Sciences and Nanotechnology 3:887-892.

Brender, MD; Erin, A; Burke, MA; Richard, M; Glass, MD (2005). Spleen Patient. Journal of the American Medical Association 294 (20): 2660.

Clement, F; Pramod, SN; Venkatesh, YP (2010). Identity of the immunomodulatory proteins from garlic (Allium sativum) with the major garlic lectins or agglutinins. Int Immunopharmacol. $10: 316-24$

Dirsch, V; Kiemer, A; Wanger, H; Vollmar, M (1998). Effects of allicin and ajoene, two compounds of garlic, on inducible nitric oxide synthase. Atherosclerosis. 139: 333-339.

Drury, RA; Wallington, EA (1976). Carleton's Histological Technique. 4th ed. London: Oxford University Press; p120-3.

Feng, Z H; Zhang, G M; Hao, TL; Zhou, B; Zhang, H; Jiang, ZY (1994). Effect of diallyl trisulfide on the activation of $\mathrm{T}$ cell and macrophagemediated cytotoxicity. J Tongi Med Univ China.14: 142-147.

Fulzele, S V; Satturwar, P M; Joshi, SB; Dorle, A K (2003). Study of the immunomodulatory activity of Haridradi Ghrita in rats. Indian J. Pharmacol. 35: 51-54.

Gomez-Flores, R; Calderon, C; Scheibel, L; TamezGuerra, P; Rodriguez-Padilla, C; Tamez-Guerra, R; Weber, R (2000). Immunoenhancing properties of Plantago major leaf extract. Phytoth Res. 14: 617-622.

Hodge, G; Hodge, S and Han, P (2002). Allium sativum (garlic) suppresses leukocyte inflammatory cytokine production in vitro: potential therapeutic use in the treatment of inflammatory bowel disease. Cytometry. 48: 209.

Lau, B; Yamasaki, T and Gridley, D (1991). Garlic compounds modulate macrophage and $\mathrm{T}$ lymphocyte functions. Mol Bioth. 3: 103-107. 
Manu, KA; Kuttan, G (2009). Immunomodulatory activities of Punarnavine,an alkaloid from boerhaavia diffusa. Immuno pharmacol Immuno toxicol. 31: 377-87.

More, P; Pai, K (2011). Immunomodulatory effects of Tinospora cordifolia (Guduchi) on macrophage activation. Biology and Medicine. 3:134-140.

Romano, E; Montano, R; Brito, B; Apitz, R; Alonso, J; Romano, M; Gebran, S; Soyano, A (1997). Effects of ajoene on lymphocyte and macrophage membrane-dependent functions. Immuno pharmacol Immuno toxicol. 19: 15-36.
Sampath, K P; Debjit, B; Chiranjib, B; Pankanas T (2010). A Traditional Medicinal herb and its health benefits. J. Chem. Pharm Res. 2(1):283291.

Szigeti, G; Pálfi,V; Nagy, B; Iné, E; Nagy, G; Szmolény, G; Bagó, G; Radványi, S (1991). New type of immune stimulant to increase antibody production generated by viral and bacterial vaccines. Magyar Allatorvosok Lapja. 120:719-721.

Tadi, P; Teel, RW; Lau, B (1990). Anticandidal and anticarcinogenic potentials of garlic. Int Clin Nutr Rev. 10: 423-429. 